\title{
Commercialization of Cattle in the Urban Markets of Yaoundé, Center Region of Cameroon: Policy Implication for an Informal Activity
}

\author{
Fon Dorothy Engwali ${ }^{1,}$, , Abdoulay Mfewou ${ }^{2}$, Hamza Moluh Njoya ${ }^{1}$ \\ ${ }^{1}$ Department of Agricultural Economics, Faculty of Agronomy and Agricultural Sciences, University of Dschang, Dschang, Cameroon \\ ${ }^{2}$ Department of Geography, Faculty of Letter and Social Sciences, University of Dschang, Dschang, Cameroon
}

Email address:

dengwali@yahoo.fr(F.D. Engwali)

${ }^{*}$ Corresponding author

\section{To cite this article:}

Fon Dorothy Engwali, Abdoulay Mfewou, Hamza Moluh Njoya. Commercialization of Cattle in the Urban Markets of Yaoundé, Center Region of Cameroon: Policy Implication for an Informal Activity. International Journal of Agricultural Economics.

Vol. 3, No. 3, 2018, pp. 37-44. doi: 10.11648/j.ijae.20180303.11

Received: March 19, 2018; Accepted: May 2, 2018; Published: May 22, 2018

\begin{abstract}
This article analyzes the functioning of the Yaoundé market through an analysis of the role of the public authorities in the functioning of the Yaoundé market, the types of economic actors involved in the commercial exchanges, the sources and the supply routes of the different marketed cattle breeds, The financial analysis of the actors involved and constraints to the development of this market through a survey of the various actors was carried out. Data was collected using a questionnaire administered to 121 respondents who were selected by the multi-stage random sampling technique. The analysis of the collected data revealed that the lifting of the health barrier established between the Far North and the Great South of Cameroon against the diseases of plague, trypanosomiasis and foot-and-mouth disease plays an essential role in the development of the Yaoundé markets. Lately, it has assumed a regional economic importance since it hosts not only the animals of North Cameroon but also those of the Central African Republic. Not according to their race or their geographical origin, the commercial value of the animals is appreciated according to their life weight, or their morphology. The financial analysis of the actors shows that this activity is profitable. However, the gross margin generated by the big butchers $(52,700$ CFA francs / beef) and the small butchers (43,500 CFA / leg of $64 \mathrm{~kg}$ ) were the most interesting. Although the market has become a supply hub for some major cities of Cameroon (Douala) and the Central African Sub Region (Libreville and Malabo), it suffers from infrastructural difficulties and a lack of transfer of competence through decentralization.
\end{abstract}

Keywords: Cattle, Commercialization, Policy, Urban-Yaoundé

\section{Introduction}

Economic activities related to cattle trade has grown significantly in Yaoundé over the last ten years with an average of 2,000 to 3,000 cattle slaughtered onthe main market day. The livestock markets of Yaoundé receive livestock not only from the large production basins of Cameroon (Adamawa, North and Far North Cameroon), but also from Chad and the Central African Republic.

Several reasons can explain the rise of cattle trade in this city. Firstly, is the fact that the routing of commercial cattle has become easier for neighbouring regions, both from North-West and the North Region of Cameroon, Chad and
Central African Republic, a country weakened by many wars including those of 1993 and 2015 [1]. Cattle rearers, mostly the PeulM'bororo, flee with their herds from conflict zones to more secure urban towns within the Central African Monetary Community (Douala, Yaoundé, Libreville, Brazzaville, and Bata). Secondly, is the population density; since densely populated urban areas (50 to 145 inhabitants / $\mathrm{km}^{2}$ ) represent a significant market for consumers of beef [1]. The third reason is the evolution of trade policies which have also facilitated the opening of breeding areas near to the main areas of meat consumption. Indeed, several authors [2, 3] have stated that during the 1980s, the livestock of NorthCameroon had few commercial outlets because of Mbés 
sanitary barrier which forbade the passage of animals from the North to the South of the country to fight against rinderpest. This sanitary barrier was abolished in 2001 .

The general and regional environment favourable to the development of the commercial activity of cattle sales, in Yaoundé markets explicitly induces a questioning: is the development of these markets possible without the accompaniment and supervision of the actors of the sector? The purpose of this article is to answer this question by making a global analysis based on five points namely: a socio-economic characterization of actors; the supply chain and possible forms of transactions through the identification of the types of economic actors involved in trade and their functions; the analysis of the cattle supply to the Yaoundé markets by highlighting the path followed by the cattle to arrive Yaoundé; the analysis of the profitability of the actors in this market; and an understanding of the institutional environment in which the cattle trade operates as well as the constraints faced by the actors.

\section{Methodology}

\subsection{Presentation of the Study Area}

The study took place in the Centre region of Cameroon specifically in the city of Yaoundé. It differs from other cities in Cameroon by its geographical location; its demographics and its economy. Yaoundéis comprised of seven (7) districts. It is located between Latitude $2^{\circ} 6$ and $6^{\circ} 14$ North and Longitude $9^{\circ} 42$ and $13^{\circ} 45$ East in the Centre Region. Yaoundé is characterized by an equatorial climate of the Guinean type, marked by two dry seasons (November to February, July to August) and two rainy seasons (March to June, August to October). The average annual rainfall is 1600 $\mathrm{mm}$ with an average temperature of $24^{\circ} \mathrm{C}$ and an annual average relative humidity of $83 \%$. The population is estimated at about 2.3 million inhabitants with an average annual population growth of $7.3 \%$ covering an area of approximately $310 \mathrm{~km}^{2}$.

\subsection{Sampling Technique and Sample Size}

By consulting the provisional directory of functional markets in the city of Yaoundé, and with the help of the Secretary General of the National Union of Butchers of Cameroon, specific markets were chosen for each Sub Division taking into account the total number of markets in each district and trading in the marketing of beef in the latter. Thus, the following eleven markets were selected: Etoudi, Mfoundi, marché du 8e, Elig-Edzoa, Essos, Ekounou, Mokolo, Mvog-Mbi, Mvog-Ada, Nsam and cattle markets. Not having a directory of butchers working in the city of Yaoundé. Ten (10) butchers in each of the markets and 50 meat retailers at the market were selectedto obtain a sample of 100 butchers and of 50 standing beef merchants. However, $121(80.7 \%)$ respondents made up of 91 butchers and 30 beef traders completely andeffectively filled the questionnaires.

\subsection{Data analysis}

The data collected was analyzed using the Statistical Package for Social Sciences (SPSS) Version 20 (SPSS 2014). Descriptive statistics were used to present the socioeconomic characteristics of livestock traders as well as the various prices involved in trade. The analysis of the operators' operating accounts allowed the highlighting of the gross margin of these actors. The gross margins were determined using the following formula:

\section{$\mathrm{GM}=\mathrm{TR}-\mathrm{TC}$}

$$
\begin{aligned}
& \text { Where } \\
& \text { GM = Gross margin } \\
& \text { TR = Total revenue (selling price) } \\
& \text { TC = Total cost }
\end{aligned}
$$

\section{Results and Discussions}

The different types of actors in the beef sector encountered in the livestock markets in Yaoundé are divided into two categories: Institutional (indirect) actors who generally play the role of facilitator and support [4] to the cattle sector and the direct actors.

\subsection{Socio-economic Characteristics of the Respondents}

This section presents the distribution of respondents

\begin{tabular}{|c|c|c|c|c|}
\hline \multirow{2}{*}{ Characteristics } & \multicolumn{2}{|c|}{ Frequency } & \multicolumn{2}{|c|}{ Percentage } \\
\hline & Butchers & Traders & Butchers & Traders \\
\hline \multicolumn{5}{|l|}{ Nationality } \\
\hline Cameroonian & 91 & 27 & 100 & 90,0 \\
\hline Chadian & 0 & 3 & 0,0 & 10,0 \\
\hline Total & 91 & 30 & 100 & 100 \\
\hline \multicolumn{5}{|l|}{ Region of origin } \\
\hline Adamawa & 12 & 15 & 13.2 & 50.0 \\
\hline Far North & 16 & 8 & 17.16 & 26.7 \\
\hline North & 8 & 5 & 8.8 & 16.7 \\
\hline West & 52 & 1 & 57.1 & 3.3 \\
\hline North-West & 2 & 1 & 2.64 & 3.3 \\
\hline Centre & 1 & 0 & 1.1 & 0.0 \\
\hline Total & 91 & 30 & 100 & 100 \\
\hline \multicolumn{5}{|c|}{ Age of respondents (years) } \\
\hline Under de 35 years & 41 & 6 & 45 & 20.0 \\
\hline Over 35 years & 50 & 24 & 55 & 80.0 \\
\hline Total & 91 & 100 & 100 & 100 \\
\hline \multicolumn{5}{|l|}{ Sex } \\
\hline Female & 0 & 0 & 0.0 & 0.0 \\
\hline Male & 91 & 30 & 100 & 100 \\
\hline Total & 91 & 30 & 100 & 100 \\
\hline \multicolumn{5}{|l|}{ Religion } \\
\hline Christianity & 8 & 0 & 8.8 & 0.0 \\
\hline Islam & 83 & 30 & 91.2 & 100.0 \\
\hline Total & 91 & 30 & 100 & 100 \\
\hline Level of education & & & & \\
\hline
\end{tabular}
according to the some socioeconomic characteristics

Table 1. Distribution of respondents according to their socio-economic characteristics. 


\begin{tabular}{lllll}
\hline \multirow{2}{*}{ Characteristics } & \multicolumn{2}{l}{ Frequency } & \multicolumn{2}{l}{ Percentage } \\
\cline { 2 - 5 } & Butchers & Traders & Butchers & Traders \\
\hline Not school & 10 & 15 & 11.5 & 48.3 \\
Primary & 41 & 8 & 44.8 & 27.6 \\
Secondary school & 38 & 6 & 41.4 & 20.7 \\
University & 2 & 1 & 2.3 & 3.4 \\
Total & 91 & 30 & 100 & 100 \\
Marital Status & & & & \\
Monogamous & 36 & 7 & 39.6 & 23.3 \\
Polygamous & 35 & 23 & 38.5 & 76.7 \\
Single & 19 & 0 & 20.69 & 0.0 \\
Widower & 1 & 0 & 1.21 & 0.0 \\
Total & 91 & 30 & 100 & 100 \\
\hline
\end{tabular}

The results in table 1show that the respondents are of two nationalities Cameroonians and Chadians. All the butchers $(100 \%)$ are Cameroonians and the largest proportion of the traders are Cameroonian $90 \%$ against $10 \%$ Chadian. This implies that the livestock markets in Yaoundéare not only supplied by cattle rearers in Cameroon, but also from Chad. The results in the table alsoindicate that activities related to the marketing of cattle and beef in the city of Yaoundé are completely male-driven (100\%).

The actors surveyed in these markets come from six regions: Adamawa, Centre, Far North, North, Northwest and West regions but the largest proportion of butchers come from the West Region (57.1\%) with a strong Islamized population (in Noun) and the Far North Region(17, 6\%).

It appears that almost all the traders in the cattle market belong to the three major cattle production basins of Cameroon that is $50.0 \%$ from Adamawa, $26.7 \%$ from the Far North and $16.7 \%$ from the North. These results justify the fact that according to [4] one does not come to the cattle trade without a strong link with the pastoral communities, nor without a long apprenticeship with the experts of the management of this activity. The Adamawa region affirms its leadership in cattle production in Cameroon. This shows that Adamawa is the country's production basin par excellence.

The level of education is a very important factor in understanding the behaviour of individuals in any study. The analysis of the level of education as presented in Table 1 shows that the majority of butchers $(44.8 \%)$ did just primary education, followed by those that did secondary education (41.4\%), and those who did not go to school (11.5\%). Those with secondary education represent only $3.4 \%$. These results are contrary to the finding of [5] in Tambacouda, Senegal, where the proportion of illiterate butchers was much higher (91\%) than those who did primary (7\%) and secondary $(2 \%)$ education. Results of this study also show that a majority of the traders surveyed (48.3\%) did not attend school; those who did primary education accounted for $27.6 \%$, and those who had attended secondary school accounted for $20.7 \%$. It can be observed that as one goes from butchers to traders, the proportion of education levels decreases. These results are similar to those found by [4] in the North of Cameroon. Indeed, the high rate of illiteracy is emblematic of the entire population of North Cameroon, which confirms the results found among traders in these markets who are mainly from the Northern regions.

The butchers surveyed are mostly married (87.1\%) against $18.7 \%$ single. The traders surveyed in the cattle market are all married (100\%) with $76.7 \%$ of polygamous versus $23.3 \%$ of monogamous. This high proportion of polygamy can be explained by the fact that polygamy is permitted in the Muslim tradition since this part of Cameroon is largely made up of Muslims.

\subsection{Supply Chain and Forms of Transactions: A Diversity of Actors}

The Yaoundé market is periodic and is held every Sunday between 8:00 am and 6:00 pm. The market is structured around a supply chain based on four different actors. The first actors are the butchers of the city who buy cattle (3 to 15 heads per butcher and per week). The second actors are exporters who buy locally (average 160 head per week), especially Goudali, M'bororo, taurin and mixedrace to export to neighbouring countries (Gabon, Congo, Equatorial Guinea). The third are the wholesalers still called traders refuelling in the collection markets, to ensure the supply (2000 to 3000 heads per main market day) so as to resale inYaoundémarkets. Finally, the last category is that of the resellers, they are considered as the category of actor who immediately buys the animals on their arrival to resell them on the spot. The latter have their purchasing power and pay the final tax. It appears the marketers or intermediaries who are very numerous are more confident in these markets.

To these four main actors, two more must be added. These are local intermediaries that play an important facilitation and marketing role. They acquire cattle from wholesalers and cattle dealers who entrust their cattle to them, then sell them and receive payment according to the agreement with the owner of the animal. They most often sell these animals at a price higher than that expected by the owner and benefit from the surplus, which is added to his remuneration. Some direct sellers ask the butchers for compensation for each negotiated sale transaction. They receive their commission from butchers as well as from traders. The mistrust of these intermediaries in these markets could be explained by the fact that their activity is prohibited by the regulations on livestock trade [4] The last actor are the Chadians and Central Africans. Indeed, it must be emphasized that the recurring political crises (1993-2015) that the Central African Republic experienced have pushed some livestock rearers in this country to get closer to the big cities of Cameroon via the Adamawa region [6]. Some of these breeders sell their animals directly to horse dealers in the Adamawa region who then ship them south by freight train or truck. Others, in search of gain, carry convoys on foot towards the cities of the South (Yaoundé, Douala...) via the Ticket-Foumban market. Thus, the distribution of cattle transportation prices by area of supply is presented in the table 2 . 
Table 2. Cattle transport prices for the Yaoundé cattle market based on supply areas.

\begin{tabular}{llc}
\hline \multirow{2}{*}{ Production zones } & \multicolumn{2}{l}{ Price per cattle head in FCFA } \\
\cline { 2 - 3 } & By truck & By train \\
\hline Maroua & 51000 & \\
Garoua & 33000 & 22000 \\
Ngaoundéré & 22000 & \\
Meinganga & 15000 & \\
Garoua-Boulai & 10000 & \\
Bamenda & 10000 & \\
Chad & 80000 \\
\hline
\end{tabular}

The sellers freely offer the prices of their animals according to the physical state, especially the stature of the life animal, and not according to their race or their geographical origin. The price is negotiated according to supply and demand. Intermediate agents play an important role in the transactions before, during and after the sale. They place themselves at the entrance of the market to offer animals to different buyers. If the intermediary succeeds in selling the animal at a price considered satisfactory, the owner of the animal gives him a commission whose amount is variable (from 5000 to 10,000 FCFA). In case of refusal to pay the brokerage commission to the intermediary, conflicts may arise after the sale. Intermediaries can earn up to 30,000 FCFA per cattle.

On their arrival and on the eve of market day, animals graze on free routes where water troughs and feeders are installed, a loading dock for large and small ruminants, a box which houses a veterinary station for control of health certificates; which also houses the of Yaounde1 council.

In order to identify it, each animal purchased is marked on the back by paint or with ear buckles. This tagging technique facilitates the recognition of purchased animals that are subsequently penned in a bold maker before being transported by truck to the slaughterhouse and/or for export.

\subsection{Livestock Market Structure}

The analysis of the structure of the beef market was done through the presentation of the particularities of the collection or local market in relation to the terminal or consumer market of Yaoundé. Livestock markets are particularly characterized by the marketing of cattle and small ruminants.

\subsubsection{Collection Market Organization}

The collection markets allow the livestock farmers to sell their livestock and the traders to stock up, they are located in the production zone or near these areas (Adamawa, Garoua, Maroua, Bamenda and Chad); they provide the supply of terminal markets. It is in these markets that traders of Etoudi cattle market come to refuel. It is strongly made up of rearers.

\subsubsection{Organization of the Consumer Market}

Terminal or consumer markets are located in major urban centres such as Yaoundé. The animals destined for slaughterhouses and the external market come from these markets [7]. Transactions take place between livestock traders and end-users (butchers, processors, consumers).

\subsection{Procurement of Yaoundé Markets: The Different Paths}

The north is the major source of supply of cattle to theYaoundé markets. This part of Cameroon presents the largest livestock production. In fact, the north, particularly the Adamawa, is the area of cattle production par excellence with the size of its herd estimated at 1,587,500 [8]. Cattle arriving in the city of Yaoundé therefore use two different routes and different means of transport (Table 2).

\subsubsection{The West Path}

The cattle track, from the west, always passes through Foumban. After crossing unhealthy plains (Tikar and Magba), the convoys of animals from the Adamawa, ascend on the Bamoun plateau with an altitude of 1,100 to 1,200 meters, which is favourable for cattle. The plateau provides a resting areas and agood pasture on the cattle pathway. This enables the animals to gain strength [9]. Once at the ticket market-Foumban, wholesalers come to refuel and will transport their animals to Yaoundé (consumption basin) where they will resell them.

\subsubsection{The Southern Path}

Yaoundé markets are supplied by cattle traders who also buy from the production areas of Cameroon and neighbouring countries such as the Chadand Central African Republic. The majority of these traders arrive with their livestock in these markets by truck, while a minority arrive by train at the Yaoundé railway station through the eastern and southern regions, before continuing their way into the markets by foot. This can be explained by the fact that the number of wagons made available to traders by CAMRAIL is insufficient [10] and also that the railway linking Yaoundé to Ngaoundéré does not continue in the other production basins (North and Far North); and also because the company CAMRAIL refuses to transport the cattle with the shepherds (map).

\subsection{Financial Analysis of Traders and Butchers}

\subsubsection{Financial Analysis of Traders}

Table 3 presents a simplified financial analysis of wholesale traders coming from different production areas in and out of Cameroon for the cattle markets in Yaoundé by truck. Results in table show that, the closer one is getting to Yaounde the higher the purchasing price of the animal of approximately the same size (200,000 FCFA, 301,500 FCFA and 317,000 FCFA as the respective prices in Maroua, Garoua and Ngaoundéré); with exceptions in Bamenda and Chad. It is the same trend with gross margins that increase $(24,500,27,400$ and 35,000FCFA respectively for traders from Maroua, Garoua and Ngaoundéré). However, transport prices per cattle head decreases while taxes and royalties (2,740FCFA) do not change 


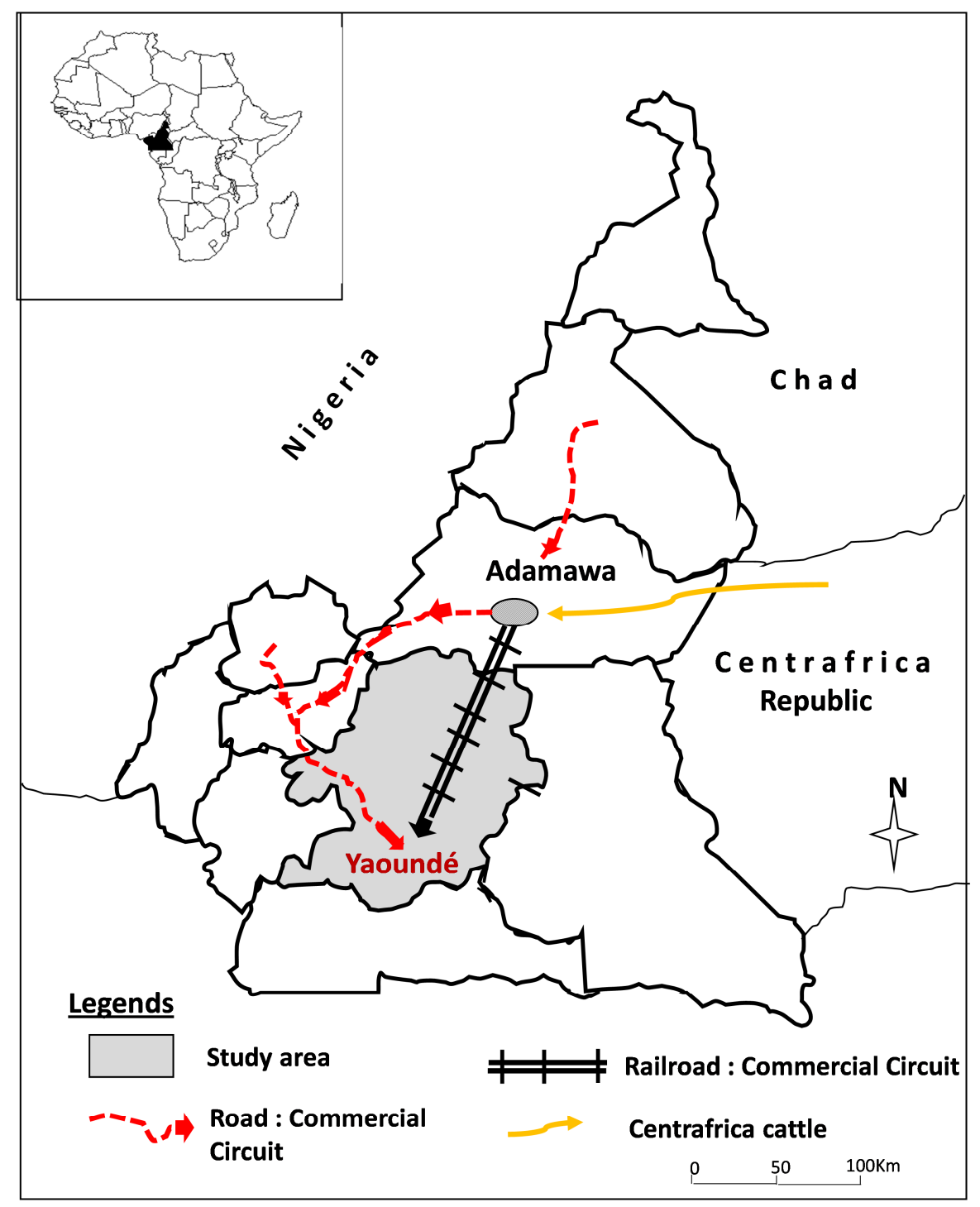

Source : Mfewou A., (2018)

Figure 1. Pathway of cattle (ruminants) to the Yaoundé markets, Cameroun.

Table 3. Financial analysisof wholesale traders.

\begin{tabular}{llllllll}
\hline Supply area & $\begin{array}{l}\text { Purchaseprice per } \\
\text { animal (FCFA) }\end{array}$ & $\begin{array}{l}\text { Taxes and } \\
\text { fees(FCFA) }\end{array}$ & $\begin{array}{l}\text { Transportcost } \\
\text { (FCFA) }\end{array}$ & $\begin{array}{l}\text { Market charge } \\
\text { (FCFA) }\end{array}$ & $\begin{array}{l}\text { Totalcost } \\
\text { (FCFA) }\end{array}$ & $\begin{array}{l}\text { Sellingprice } \\
\text { (FCFA) }\end{array}$ & $\begin{array}{l}\text { Grossmargin } \\
\text { (FCFA) }\end{array}$ \\
\hline Maroua & 200,000 & 2,740 & 51,000 & 4,200 & 257,940 & 282,440 & 24,500 \\
Garoua & 301,500 & 2,740 & 33,000 & 4,200 & 341,440 & 368,840 & 27,400 \\
Ngaoundéré & 317,000 & 2,740 & 22,000 & 4,200 & 345,940 & 380,940 & 35,000 \\
Bamenda & 280,000 & 2,740 & 10,000 & 4,200 & 296,940 & 313,440 & 16,500 \\
Tchad & 200,000 & 2,740 & 80,000 & 4,200 & 286,940 & 306,940 & 20,000 \\
\hline
\end{tabular}

Animals are sold more expensive in Ngaoundere, and provide a higher gross margin (35,000 CFA). Thiscan be explained by the fact that the animals there are mostly of the race Goudali. This race is not only the highest in Adamawa but also highly reputed for its good stature and highquality meat; and moreover the transport is less expensive. This gross margin value is similar to that found by [11] of 29,317FCFA for a Ngaoundere trader going to Yaoundé.

Table 4. Financial analysis of beef resellers.

\begin{tabular}{|c|c|c|c|c|c|}
\hline Resellers & Purchaseprice (FCFA) & Marketcharge (FCFA) & Total cost (FCFA) & Selling Price (FCFA) & Grossmargin (FCFA) \\
\hline Maroua & 282,440 & 4,200 & 286,640 & 298,140 & 11,500 \\
\hline Garoua & 368,840 & 4,200 & 373,040 & 385,940 & 12,900 \\
\hline Ngaoundéré & 380,940 & 4,200 & 385,140 & 399,740 & 14,600 \\
\hline Tchad & 306,940 & 4,200 & 311,140 & 322,140 & 11,000 \\
\hline
\end{tabular}


The same observationtrendsas in Table 4 are evident for the evolution of purchase prices of these animals in Yaoundé and gross margins. Except that the different purchase prices of reseller $(282,440,368,840,380,940,313,440$ and 306,940 FCFA) respectively for animals from Maroua, Garoua, Ngaoundere, Bamenda and Chad are higher than for wholesalers. On the other hand, their gross margins $(11,500$; 12,$900 ; 14,600 ; 9000$ and 11,000FCFA) are lower than those of wholesalers. These different resellers purchase prices observed, could be due to the multiple charges that the wholesalers undergo (transport, taxes and fees...) before reaching Yaoundé. Resellers' selling prices are the same like the purchase prices of butchers in this market if they buy directly from wholesalers. However, these butchers may rarely have the chance to buy their cattle directly from wholesalers just because they have to sell the meat stock of the past week to get the money.

\subsubsection{Financial Analysis of Butchers}

The financial analysis of the butchers after purchase of beef is presented in tables 5 and 6 . An average cattle of life weight was considered at a price of 308 500FCFA in Table 5 and the medium leg of $64 \mathrm{Kg}$ was considered in Table 6 for small butchers. In fact for an animal of about 308 500FCFA, the weight of the carcass would approximately be $168 \mathrm{~kg}$. Sold at the wholesale price per kilogram (1900FCFA / kg) the carcass would amount to 319200FCFA. As for the 5th quarter (offals) of the carcass, the average price is estimated at 60 000FCFA, resulting in a total income of 380 000FCFA. The result or the gross margin is 52700FCFA for big butchers and 43500 FCFA for small butchers.

Table 5. Financial analysis for the big butchers.

\begin{tabular}{llll}
\hline Total costs (TC) & & Total revenue (TR) & Value \\
\hline Items & Value & Item & 319200 \\
\hline Purchaseprice of animal & 308500 & Sellingpricecarcass & \\
Butchersassistant & 2000 & & \\
Slaughteringfee & 10300 & Selling price 5th quarter (offals) & 60000 \\
taxes (council + veterinary) & 700 & & \\
Transport to sheds & 3000 & & 379200 \\
Refrigerationfee & 300 & TR & \\
Cattlemaintenance & 1700 & & \\
TC & 326500 & 52700 & \\
GM & & & \\
\hline
\end{tabular}

Table 6. Financial analysis for the small butchers.

\begin{tabular}{llll}
\hline Total costs (TC) & & Total revenue (TR) & \\
\hline Item & value & Item & value \\
\hline Purchase price of quarter (1 leg) of 64 Kg & 121600 & Sellingprice, of leg & 166400 \\
Transportfee & 1000 & & 166400 \\
Refrigerationfee & 300 & TR & \\
TC & 122900 & & \\
GM & 43500 & & \\
\hline
\end{tabular}

All these results are lower than those found by [12] in Central Africa where the gross margin of butchers was estimated at 107,000 FCFA for an average cow. This low gross margin for butchers can be explained by the presence of middlemen who are the origin of the auction at the expense of butchers in the livestock market of Yaoundé.

The analysis of the operating account of the various operators involved in the marketing of live cattle shows that this activity is profitable for all of these operators. However, the gross margins generated by the big butchers $(52,700 \mathrm{CFA}$ / beef) and the small butchers (43,500 CFA / leg of $64 \mathrm{~kg})$ are the most interesting. Wholesale traders buying cattle in the Maroua, Garoua, Ngaoundéré, Bamenda and Chad production basins $(24,500,27,400,35,000,16,500$ and 20000 CFA respectively) and beef dealers from Maroua, Garoua, Ngaoundéré, Bamenda and Chad (11500, 12900, 14600, 9000 and 11000 respectively) also remain important.

\subsection{Institutional Environment: Weak Intervention of Ministries and Services Involved in Trade}

Institutional actors, also called indirect actors, include veterinary agents, communal agents of Yaoundé I, financial agents (Auxiliary of Taxes), market guard and the Trade Commissioner. In general, they play a role of facilitator and support [4] in the standing beef sector. For this purpose, the veterinary agents ensure the sanitary control of the animals which arrive on the market and gains at the end of this activity the tax of sanitary inspection at the rate of 200 FCFA per head. They establish a health $\log$ which testifies to the good state of health of the animal, which secures the transfer of animals to areas or centres of consumption. The Yaoundé1Mayor levies communal taxes, at the rate of 500 FCFA per head for livestock. Finance officers collect the tax on the internal movement of livestock. The guardian ensures the safety of the animals in the market and in the end the 
market delegates ensure the proper functioning of the market, intervening in case of problem between seller and buyer. Conflicts can arise from the sale of the same animal to two different buyers. Indeed the intermediary can sell the animal and the owner resells to another buyer, which creates conflicts that the delegate must solve.

In the Yaounde market, the role of the various ministries in charge of trade is weak, although the institutional framework (municipal agent, finance officer and veterinary officer) exists. The statistical service which is absent could contribute to the development process through research [1]. In addition to the lack of representation from different ministries, no police service ensures the safety of people and goods in the marketplace as there is only one security officer, also known as the security guard. Given the size of this market and the interesting numbers of cattle (about 3500 heads) arriving every day on the market, one might think that the total of these indirect actors is insufficient. This insufficient number of indirect actors, particularly as a security guard, is at the origin of the theft of animals in this market. In addition, the insufficient presence of veterinarians is the result of several unhealthy cattle which after slaughter are seized after inspection at the slaughterhouse. The weak transfer of powers from the state to local authorities, through the example of the market, is due to a still embryonic decentralization in Cameroon, which remains political.

\subsection{Constraints Faced by Butchers and Traders}

\subsubsection{Constraints Evoked by butchers}

Table 7 shows the distribution of butchers according to the constraints encountered during the purchase of cattle.

Table 7. Distribution of butchers according to their constraints faced in cattle business.

\begin{tabular}{lll}
\hline Constraints & Frequency & Percentage \\
\hline Access to credit & 16 & 17.6 \\
Tax & 33 & 36.3 \\
Market regulation & 25 & 27.5 \\
Sanitary & 28 & 30.8 \\
Infrastructures & 53 & 58.2 \\
Slaughter house constraints & 46 & 50.5 \\
Supply & 48 & 52.7 \\
Intermediary & 60 & 65.9 \\
\hline
\end{tabular}

The major difficulties are the presence of many intermediaries (65.9\%), market infrastructures (58.2\%) availability of supply $(52.7 \%)$ which sometimes translates into lack of beef slaughterhouse-related constraints (50.5\%), taxation $(36.3 \%)$, sanitary control $(30.8 \%)$.. The excess of middlemen, which is the main constraint of butchers, can be explained by the fact that these butchers do not buy their animals directly from wholesalers when they arrive at the market. The traders prefer either to sell them to resellers or to get along with an intermediary for a certain price. These animals thus pass from intermediary to intermediary (between 2 to 3 passes) before being sold to butchers or exporting traders which raise the bidding at each handover.

\subsubsection{Constraints Faced by Traders}

The main constraints mentioned by surveyed traders (wholesalers) and resellers are presented in Table 8.

Table 8. Distribution of traders according to constraints faced in cattle business.

\begin{tabular}{lll}
\hline Constraints & Frequency & Percentage \\
\hline Access to credit & 5 & 16.7 \\
Tax & 6 & 20.0 \\
Market regulation & 2 & 6.7 \\
Sanitary & 1 & 3.3 \\
Infrastructures & 16 & 53.3 \\
Slaughterhouse constraints & 1 & 3.3 \\
Supply & 17 & 56.7 \\
Theft & 13 & 43.3 \\
Climate change & 15 & 50.0 \\
Lack of weighing infrastructure & 16 & 53.3 \\
Lack of boarding and landing infrastructure & 10 & 33.3 \\
\hline
\end{tabular}

It appears from table 8 that, the major constraints mentioned by wholesalers during the supply and marketing of cattle at the Yaoundé livestock market are many. Supply availability $(56.7 \%)$, market infrastructure $(53.3 \%)$, lack of weighing equipment $(53.3 \%)$, climate change $(50 \%)$, livestock theft $(43.3 \%)$, lack of loading and offloading infrastructure (33.3\%), access to bank credit (16.7\%) and taxation (20\%) are not as negligible. Market regulations, veterinary inspection (3.3\%) and slaughterhouse constraints (3.3\%) seem to affect less wholesale traders and livestock resellers.

\section{Conclusion}

The current influx of livestock to the Yaoundé markets is linked to two changes that have occurred: the upliftment of the old sanitary barrier between North and South Cameroon and the addition of Central African and Chad cattle rearers who have fled from recurrent political crises from their countries. Since then, the Yaoundé markets have become a hub for receiving and transacting life animals, in the direction of major consumer catchment areas in South Central Africa: Cameroon (Douala and Yaoundé), Gabon (Libreville) and Equatorial Guinea (Malabo).

All actors involved in the cattle business acquire some financial gain- profitable business. Therefore, a better involvement of the State will be desirable in order to improve the Yaoundé commercial site by building infrastructures and improving the reception of the actors. In the future, a predictable increase in livestock transactions and marketgenerated tax revenues can be fully supported in the context of decentralized market management or it will require a parallel presence of the State.

\section{References}

[1] Mfewou A., Njoya A., OyepEngola J., 2016a. Globalization, variability of the business of cattle and the beef in Central Africa. European Universities Editions. 
[2] Boutrais, J., Herrera, J., Bopda, A. (1992) Cattle, naira and CFA franc, a cross-border flow between Nigeria and Cameroon. $12 \mathrm{p}$.

[3] Awa, D. N., Njoya, A., Mopate, Y. L., Ndomadji, J. A., Onana, J., Awa, A. A.,... and Maho, A. (2004). Constraints, opportunities and evolution of livestock breeding systems in the semi-arid Central African region. Cahiers Agricultures, 13 (4), 331-340.

[4] Djamen P. N.., 2008. Territory, marketing channel and time: modalities and stakes of commercial insertion oflivestock farming systems in North Cameroon. Thesis; 296p.

[5] Duvergé., 2006. What future for the sector beef of Senegal? Study of the long circuit of the sector, Tambacounda to Dakar. $105 \mathrm{p}$.

[6] Kadekoy-Tigague, D. (2001). Cattle Marketing in Central African Savannahs: realities and prospects. ICRA/PRASAC, 50 .

[7] Kadekoy Tigague D., 2008. Cattle marketing in Central
African Republic: Trans-border frontier dynamics, Bangui, Central African Republic, CIRAD-PRASAC 25p.

[8] Ministry of the Breeding of Peach and the Animal Industries (MINEPIA). 2013, Contribution of the beef to the Cameroonian economy. $6 \mathrm{p}$.

[9] Mfewou A., Boutrais J. et Poutougnigni Y 2016b. Dynamics and Constraints of Ticket-Foumban livestock market development in the West of Cameroon. Canadian Review of Tropical Geography Vol. 3 (2): 43-52.

[10] Ministry of the Breeding of Fishing and the Animal Industries ( MINEPIA), on 2009 in Master plan for the development of the sectors of the breeding in Cameroon. Flight 2: mapping of the sectors, Yaoundé, Cameroon.

[11] Duteurtre G., MianOudanang K., Timothee E., KadekoyTigague D., 2003. Cattle Marketing in Central African Savannahs: realities and prospects. CIRAD - PRASAC, 7 p.

[12] Kadekoy-Tigague D., 2003. Profitability and dynamics of live cattle trade in Central African Republic, ICRA-PRASAC 25p. 